\title{
Lumbar facet synovial cyst
}

\section{N V Deshmukh, P Kanse}

Answers on $p 423$.

$A^{\top}$

75 year old woman presented to the orthopaedic clinic with low back pain and left leg pain for last three months. The low back pain was of gradual onset and was progressive. The pain was aggravated on walking and standing. On clinical examination the patient was fit and well. She had bilateral free straight leg raise. Femoral nerve stretch test on the left leg was positive. She was intact neurologically and the range of movements in the spine were terminally restricted. Both hips and sacral iliac joints were clinically normal. A clinical diagnosis of lateral canal stenosis was made.

Magnetic resonance imaging (MRI) of the lumbosacral spine revealed a well defined posterolateral extradural cystic mass (see fig 1). It had a low intensity wall signal and a high intensity content signal. Associated degenerative and spondylolisthetic spine was noted. The cyst was in continuity with the degenerative facet and gadolinium enhancement of the cyst showed a lumbar facet synovial cyst.

\section{QUESTIONS}

(1) What is a lumbar facet synovial cyst?

(2) How is it diagnosed?

(3) How is it treated?

Postgrad Med J 2003;79:419

\section{Authors' affiliations}

N V Deshmukh, P Kanse, Department of Orthopaedics and Trauma, Withybush General Hospital, Haverfordwest

Correspondence to: Dr Deshmukh; deshmukh_nitin@hotmail.com

Submitted 10 June 2002

Accepted 22 July 2002

\section{A misleading swelling of the tongue}

\section{Simon, T Somanathan, M Pandey}

Answers on $p 424$.

A 41 year old Indian man presented with a swelling on the tip of the tongue of six months' duration. He reported having irregular sharp teeth that caused repeated ulceration on the tongue, for which he had earlier sought

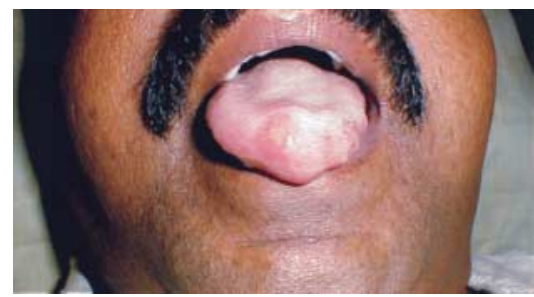

Figure 1 Clinical photograph showing submucosal swelling at the tip of the tongue. orthodontic therapy. Intraoral examination revealed a $2 \times 2 \mathrm{~cm}$ hard multilobulated swelling, exhibiting a smooth mucosal surface, situated at the tip of the

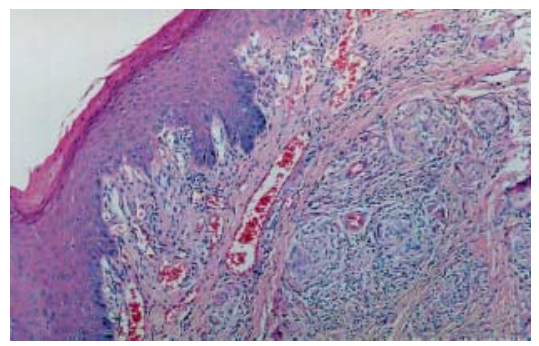

Figure 2 Photomicrograph showing many closely packed granulomas seen below the stratified squamous epithelium (haematoxylin and eosin $\times 100$ )
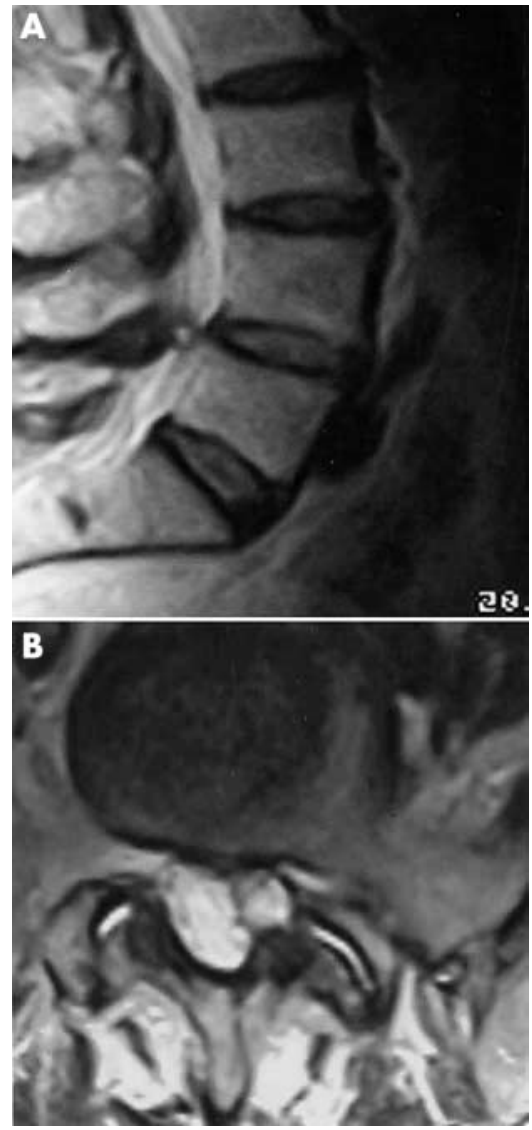

Figure 1 (A) and (B) MRI scans of the lumbar spine showing a well defined extradural cyst on the posterolateral aspect.

oral tongue (fig 1). Cervical lymphadenopathy was absent. Systemic examination was normal. The haematological and biochemical parameters failed to reveal any abnormality and the chest radiograph was normal. A wide excision of the lesion with primary closure was carried out.

On gross examination, the specimen measured $2.5 \times 2.5 \times 1.5 \mathrm{~cm}$ and was covered with mucosa showing an irregular grey-white area measuring $1.5 \times 1 \mathrm{~cm}$ extending close to deeper margin of

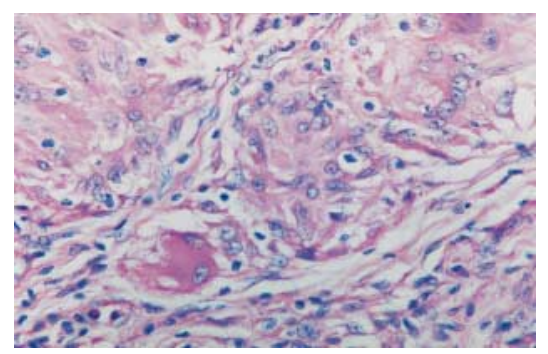

Figure 3 Photomicrograph showing granulomas composed of epithelioid cells, few lymphocytes and a giant cell with an asteroid body (haematoxylin and eosin $x$ 400). 
excision. Microscopic examination revealed the lining stratified squamous epithelium with plenty of closely packed,

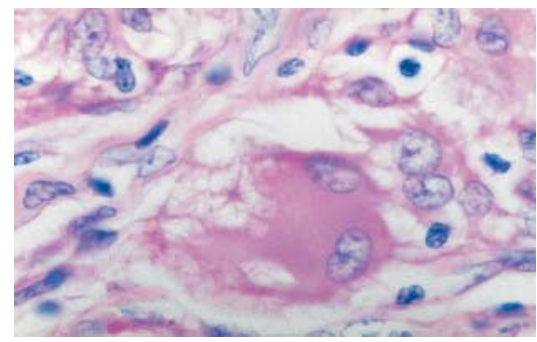

Figure 4 Photomicrograph showing giant cell with a stellate, spider-like asteroid body in the cytoplasm (haematoxylin and eosin $x$ 1000). well demarcated, non-caseating granulomas in the underlying connective tissue (fig 2). These granulomas were composed of epithelioid cells, few lymphocytes, occasional plasma cells, and multinucleated Langhan's and foreign body type of giant cells (fig 3). Some of the giant cells showed reddish-pink, spider-like, stellate inclusions (asteroid bodies) within the cytoplasm (fig 4). There was no evidence of necrosis.

\section{QUESTIONS}

(1) What is the differential diagnosis for this lesion?

(2) How will you establish a definitive diagnosis and suggest the investigations necessary for the same?
(3) Discuss the prognosis and treatment of this lesion?

Postgrad Med J 2003;79:419-420

\section{Authors' affiliations}

D Simon, M Pandey, Department of Surgical Oncology, Regional Cancer Centre,

Trivandrum, India

T Somanathan, Department of Pathology

Correspondence to: Dr Manoj Pandey, Department of Surgical Oncology, Regional Cancer Centre, Medical College PO, Thiruvananthapuram, Kerala 695011 , India; manojpandey@rcctvm.org/mpandey@hclinfinet.com

Submitted 9 August 2002

Accepted 21 October 2002

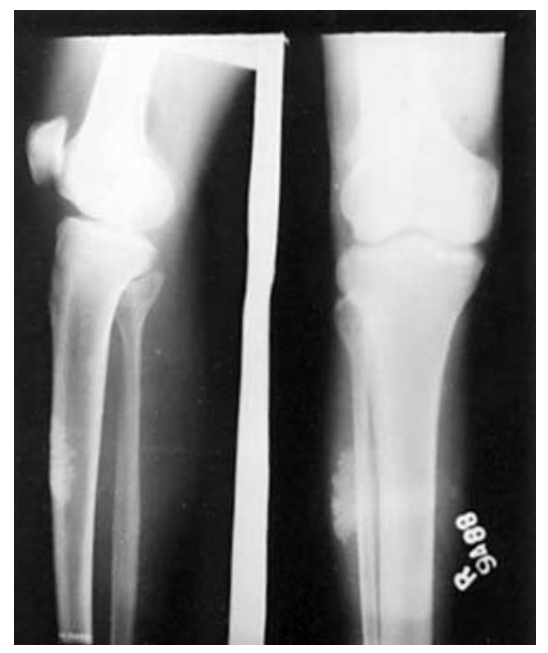

Figure 1 Lateral and anteroposterior radiographs of leg showing the lesion. on the anterior aspect of middle thirds of his right leg draining a milky white fluid with a viscosity of that of water. There was an area of $3 \times 2 \mathrm{~cm}$ around the sinus that was indurated. Radiography of the leg showed a radio-opaque lesion in the subcutaneous tissue (fig l). No irregularity or abnormality was detected in either bone of the leg. Bacteriological examination of the fluid was negative as was the $\mathrm{KOH}$ mount done to exclude a fungal infection. His blood counts were neutrophils $76 \%$, lymphocytes $20 \%$, monocytes $2 \%$, eosinophils $2 \%$, and his blood cultures were negative. Blood chemistry, renal function, and liver function were all normal. Detailed examination of other extremities and their radiological surveys were non-informative. A fine needle aspiration cytology (FNAC) smear was taken and revealed a few red blood cells against a proteinaceous background. An incision biopsy was planned but on incision, only some chalky white fluid identical to the discharge was drained out. Histopathological examination of the material duplicated the FNAC findings. Alizarin red S staining demonstrated characteristic birefringence.

\section{QUESTIONS}

(1) What is the diagnosis?

(2) What other features can be associated with the present clinicoradiological picture?

(3) Which immunological test is positive in a majority of patients with this clinical condition?

Postgrad Med J 2003;79:420

\section{Authors' affiliations}

K M Marya, V Yadav, Department of Orthopaedics, Paraplegia, and Rehabilitation,

Postgraduate Institute of Medical Sciences, Rohtak, India

Correspondence to: Dr K M Marya, S S R

Medical College, Belle Rive, Mauritius; dr_marya@hotmail.com

Submitted 21 September 2002

Accepted 19 December 2002 